\title{
ARISTOTLE'S CONTRAST BETWEEN EPISTEME AND DOXA IN ITS CONTEXT (POSTERIOR ANALYTICS I.33)
}

\author{
LUCAS ANGIONI \\ https:/ / orcid.org/0000-0002-3265-5330 \\ University of Campinas \\ Department of Philosophy \\ Campinas, SP \\ Brazil \\ angioni.lucas@gmail.com
}

\author{
Article info \\ CDD: 185 \\ Received: 02.10.2019; Accepted: 07.10.2019 \\ DOI: http://dx.doi.org/10.1590/0100-6045.2019.V42N4.LA
}

\section{Keywords \\ Aristotle \\ Explanation \\ Demonstration \\ Epistemology \\ Essencialism}

\begin{abstract}
Aristotle contrasts episteme and doxa through the key notions of universal and necessary. These notions have played a central role in Aristotle's characterization of scientific knowledge in the previous chapters of APo. They are not spelled out in APo I.33, but work as a sort of reminder that packs an adequate characterization of scientific knowledge and thereby gives a highly specified context for Aristotle's contrast between episteme and doxa. I will try to show that this context introduces a contrast in terms of explanatory claims: on the one hand, episteme covers those claims which capture explanatory connections that are universal and necessary and thereby deliver scientific understanding; on the other hand, doxa covers the explanatory attempts that fail at doing so.
\end{abstract}




\section{INTRODUCTION}

In Posterior Analytics I.33, Aristotle presents a contrast between episteme and doxa. A translation of these terms as knowledge and belief might give the wrong impression that Aristotle is engaged with some general epistemological distinction between the cognitive states that are so labeled in contemporary discussion. But Aristotle is not engaged with that issue. Aristotle is employing 'episteme' in a reasonably consistent way since the beginning of the Posterior Analytics (henceforth APo): at 71b9-12, the expression 'epistasthai haplos' introduces the definiendum that will guide his ensuing discussion, and thenceforth the relevant occurrences of the term 'episteme' introduce a higher sort of knowledge that is defined by the grasping of explanatory connections. ${ }^{1}$ 'Scientific knowledge' is a reasonable translation of what 'episteme' conveys in those contexts. On the other side of the contrast, 'doxa' is not recurrent in the previous chapters of the Posterior Analytics. But, as I will argue, Aristotle employs 'doxa' in APo I.33 to refer to a subset of opinions, namely, those that present explanatory claims that might seem to satisfy the criteria for the higher sort of knowledge labeled 'episteme'.

Aristotle contrasts episteme and doxa through the key notions of universal and necessary. These notions have played a central role in Aristotle's characterisation of scientific knowledge in the previous chapters of $A P o$. They are not spelled out in I.33. They work as a kind of reminder, which abbreviates an adequate characterisation of scientific knowledge-and thereby gives a highly specified context for Aristotle's contrast. I will show that this context introduces

1 On what is the definiendum in 71b9-12, see Angioni 2016, p. 141-3. I am in line with Taylor 1990, p. 120-2; Fine 2010a, p. 1389; Goldin, 2013, p. 199-20. For discussion, see Ferejohn 2013, p.66-72; Bronstein 2016, p. 52-3. 
a contrast in terms of explanatory claims: on the one hand, episteme covers those claims which grasp explanatory connections that are universal and necessary and thereby deliver scientific understanding; on the other hand, doxa covers the explanatory attempts that fail at doing so.

Of course, this does not imply that every doxa involves an explanatory claim. Aristotle agrees that it is possible to have an opinion about (e.g.) Socrates being seated with no clue about what makes Socrates be seated. But the contrast between episteme and doxa in APo I.33 is strictly focused on opinions expressing explanatory claims. Such a restriction is a natural step in the context of $A P o$, for Aristotle has characterised episteme in terms of grasping explanatory connections. ${ }^{2}$ When he starts I.33, his purpose is to delineate the difference between scientific knowledge (i.e., the higher form of knowledge defined by the grasp of appropriate explanations) and a specific kind of opinion that could easily be confounded with scientific knowledge, namely, the kind of opinion expressing explanations that are not the ultimate ones. His motivation for this contrast can be well understood in $A P o$ as a whole: since the first characterisation of scientific knowledge (71b9-12), Aristotle has contrasted it with a different and inferior way of grasping explanatory connections - the kata sumbebekos knowledge, which selects explanatory factors that are inappropriate or even irrelevant, but might be manipulated by sophists to produce a false semblance of being

2 I follow Burnyeat 1981, p. 101, 137; Matthen 1981, p. 3-10; Kosman 1973, 1990, p. 354-5; Lesher 2001, p. 46; and Taylor 1990: an epistemological standpoint is not central for Aristotle's characterisation of episteme in APo (I add: nor even for the contrast between episteme and doxa in I.33). 
knowledgeable. ${ }^{3}$ Thus, it is a natural move for Aristotle in this context to restrict himself to that particular kind of doxa that is an inferior kind of explanatory knowledge.

Thus, Aristotle's contrast between episteme and doxa in APo I.33 hinges on the notion of explanatory appropriateness. We should not take Aristotle in APo I.33 as saying something like this: 'I have said all you need to know about episteme, now I am going to tell all you need to know about doxa. His aim is much more modest and connected to the content of the treatise. Traditionally, the contrast has been understood as saying that episteme is the cognitive state that grasps propositions like 'every human is mortal' as universal and necessary truths (or even as essence-based necessary truths). However, as I will argue, this is not how the notion of 'necessary' was crucially used to characterize episteme in APo. Besides, the notion of universality as displayed in that proposition does not correspond to how the notion of 'universal' was crucially used to characterize episteme in APo. The notion of episteme has been characterised in terms of grasping explanatory connections. In $A P o$ I.33, Aristotle is following a strategy that he has adopted many times in the previous chapters of the treatise, namely, to stress that the explanatory knowledge displayed in episteme is superior to other sorts of explanatory claims. ${ }^{4}$ Now, it would be a very futile strategy for Aristotle to stress the superiority of episteme by contrasting it with the opinion that (e.g.) Socrates is seated, which does not involve any explanatory claim at all. Thus, far from aiming at an overarching characteristion of what

${ }^{3}$ See Angioni 2016 for this view about 71b9-12. See Fine 2010b, p. 146-8 for a similar but different approach to 'kata sumbebekos knowledge'.

${ }^{4}$ Here is a modest list: 74a4-32;75b37-76a10; 76a28-30; 78a23-28, b13-28. I will deal with some of these passages in the next sections. 
doxa in general is, Aristotle's discussion focuses on the subset of doxai that advance explanatory claims.

\section{THE KEY NOTIONS IN THE CONTRAST: UNIVERSAL AND NECESSARY.}

Instead of examining the whole chapter I.33, my discussion will be restricted to the first part of it $-88 \mathrm{~b} 30$ $89 \mathrm{a} 10 . .^{5}$

Aristotle hinges the contrast on two key notions, the universal and the necessary, as follows:

T1: 'Scientific knowledge and its object are different from opinion and its object, because scientific knowledge is universal and depends on necessary items, and what is necessary cannot be otherwise. There are some items that are true, i.e., they are the case, but they can be otherwise. It is clear, then, that there is no scientific knowledge involving them' (88b30-34, Barnes's translation modified).

Remarkably, the two key notions seem to carry the burden of giving an adequate characterisation of episteme or, at least, of the contrast between episteme and doxa. To be sure, there are other passages in Aristotle's works in which he gives sketchy outlines of what scientific knowledge or demonstration is (cf. Topics 100a27-b21, EN VI.3). But the position of APo I.33 inside the treatise strongly suggests that the pair of key notions was chosen as an appropriate

${ }^{5} \mathrm{~A}$ full discussion of the intricate argument of the remaining sections of the chapter will require another paper. Actually, I have already spelled out my view in Angioni 2013. See Fine 2010a, Morison (forthcoming), Peramatzis (forthcoming). 
reminder for the full characterisation of episteme as scientific knowledge. Now, if one tracks how Aristotle has resorted to these notions in his previous discussion, one will find them in contexts that involve explanatory appropriateness. Once their full significance is unpacked, the two key notions show themselves as encapsulating what is most important for episteme to be different from doxa. This is what I will explore in the next sections.

\section{THE UNIVERSAL: UNIVERSAL PREDICATIONS AND UNIVERSAL DEMONSTRATIONS.}

I start with the 'universal' (katholou), which is used in $A P o$ I.4 to introduce a key notion in Aristotle's theory of scientific demonstration. ${ }^{6}$ The first relevant passage reads thus:

T2. 'I call universal what holds of every case and in itself and as such' (73b26-7, Barnes's translation).

Taking this passage together with what is added at 73b32-3, we can characterise the universal by the conjunction of three conditions: the universal is a predicate that:

(i) belongs to every extension of its subject;

(ii) is coextensive with its appropriate subject;

\footnotetext{
${ }^{6}$ Ross (1949, p. 523) was wrong in saying that this use of the term is sui generis, not to be found in the other treatises. See McKirahan 1992, p. 184-5; Charles 2000, p. 207-9; Lennox 2001b, p. 46-7; Ferejohn 1994, p. 85-6; Ferejohn 2013, p. 83-90; Hasper \& Yurdin 2014, p. 130-7; Angioni 2016, p. 147-9; Angioni 2018. I disagree with Smith 1984, p. 63.
} 
(iii) belongs to its subject in itself and qua itself.

Since condition (ii) entails condition (i), they can be packed together into one single extensional requirement the coextensiveness requirement - , whereas condition (iii) presents an intensional requirement: its belonging must be grounded in the essence of its appropriate subject -and this probably accounts for its necessity too (cf. 73b27-8). Thus, it results that katholou is a predicate that is coextensive with its appropriate subject and, besides, belongs to its subject in virtue of what it is in itself and qua itself. 7

Now, my question is what Aristotle means when he says that episteme is universal in $\boldsymbol{T} 1$. One suggestion would be that coextensive universal statements (e.g., 'every triangle has 2R') are the appropriate subject-matter of episteme, instead of mere universal statements (e.g., 'every horse is an animal'). But this suggestion is unattractive: first, because it will imply that there can be no opinion about coextensiveness statements and, most importantly, because it ignores that no sufficient characterisation of episteme can be reached by focusing on the logical form of bare statements, for Aristotle stresses that scientific knowledge of each thing involves knowing that its cause is indeed its cause (71b9-12). Given this characterisation of episteme in terms of grasping explanatory relations, it is fair to expect that the notion of universal in $\boldsymbol{T} \mathbf{1}$ has some special connection with the requirement of knowing each thing through its cause. It is fair to expect that the notion of universal must be tied with the notion of knowing appropriate explanatory connections. Now, does Aristotle

7 I don't need to discuss some intricacies. See Ross 1949, p. 5223; Inwood 1979; McKirahan 1992, p. 95-8; Barnes 1993, p. 118-9; Goldin 1996, p. 145-6; Lennox 2001a, p. 9; Hasper 2006, p. 26978; Ferejohn 2013, p. 83-90; Hasper \& Yurdin 2014, p. 131; Bronstein 2016, p. 47-8, Angioni 2016, p. 147-8; Zuppolini 2018. 
make this further move of associating the notion of universal with the notion of knowing appropriate explanatory connections? I argue that he does - starting precisely in the next lines after presenting katholou as a special kind of predicate.

Up to 73b39, the universal was treated as a special kind of predicate. The features that define it focus strictly on the relation between the subject and the predicate of a given sentence. However, in 74a1-3, Aristotle uses the term 'universal' (katholou) in connection with demonstrations (not merely predications). The translation runs as follows:

T3. '(i) the demonstration [sc. of $2 \mathrm{R}]^{8}$ which takes it [sc. the triangle] in itself is universal, (ii) but in a way it does not take the others [sc. each species of triangle] in themselves, (iii) nor does it apply to the isosceles universally' (74a1-3, my translation).

The Greek is very compact, there being many reasonable construals which make good sense of the syntax. The two occurrences of 'katholou' $(74 \mathrm{a} 1,3)$ can be taken adverbially as ranging over the subject-terms of the suggested conclusions of each demonstration (namely, the triangle and the isosceles triangle). This is how Barnes (1993, p. 8) has translated: 'the demonstration applies to it universally in itself $[\ldots]$ - it does not apply to the isosceles universally'. However, I prefer to take at least the first occurrence of 'katholou' (at 74a1) as an adjective applied to 'apodeixis', with the result of introducing the notion of a universal demonstration. ${ }^{9}$ This notion, which will explicitly

8 ' $2 R$ ' is the traditional abbreviation for the attribute of having the sum of internal angles equal to two right angles.

${ }^{9}$ McKirahan 1992, p. 96 (in his remark 'a'), suggests that katholou is an adjective in $74 \mathrm{a} 1$, but he has actually translated it as an 
appear again in APo I.5 and I.24, is the highest desideratum for attaining scientific understanding of a given explanandum. ${ }^{10}$ The demonstration of (e.g.) $2 \mathrm{R}$ qualifies as universal when it jointly satisfies two conditions, namely, when it identifies the subject which is commensurate to $2 \mathrm{R}$ and captures the exact ground that explains why $2 \mathrm{R}$ belongs to that subject in itself. Aristotle's train of thought in $\mathbf{T 3}$ is this: (i) the demonstration is universal when it takes the triangle in itself, for, in that case, the demonstration not only gets the right commensurate subject of $2 \mathrm{R}$, but also picks out the right explanatory factor, in terms of what the triangle is in itself; ${ }^{11}$

adverb. I add a good (but, of course, not decisive) reason for preferring my syntactic construal. Note that the first occurrence of 'katholou' in 74a1 is accompanied by 'kath' hauto'. Now, since Aristotle has insisted in the previous section of I.4 that every katholou predicate takes its subject kath' hauto (73b26-7, 28-32), it would be redundant to have both katholou and kath' hauto as ranging over the subject of the implied conclusion (i.e., triangle) for, if the triangle is taken katholou, it is thereby taken in itself too.

${ }^{10} \mathrm{My}$ italics in the expression 'scientific understanding of a given explanandum' is important. Universal demonstrations are the highest desideratum for scientific understanding of a given explanandum, but this does not imply that a body of scientific knowledge will only have universal demonstrations. Aristotle's issue in the passages discussed in this paper is exactly what it is for an explanation of a given explanandum to be the most appropriate one, and his answer follows this line: the most appropriate explanations are the universal explanations. Another important issue is what a body of expert knowledge consists in, but Aristotle's answer will not say that a body of expert knowledge must include only universal demonstrations. A body of expert knowledge also includes (besides other things) what McKirahan (1992), p. 177-87, has called 'application arguments'. I develop the distinction between these issues in Angioni (2018b) and Angioni (forth.).

${ }^{11}$ I take ' $\kappa \alpha \theta$ ' avió' in 74a1 (as well as in 73b27) with the force

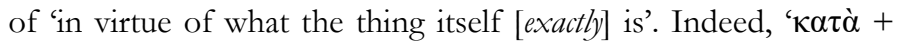


(ii) this demonstration in a way does not take the others in themselves, namely, it does not rest on what each of the triangles is specifically in itself (e.g., it does not take its explanatory factor in terms of what makes the isosceles triangle specifically isosceles); (iii) nor does the universal demonstration apply to the isosceles universally, because the isosceles is not even commensurate with $2 \mathrm{R}$, and what the isosceles triangle itself is qua isosceles (namely, a triangle with two sides equal to each other) does not pick out the appropriate factor for explaining $2 \mathrm{R}$.

Thus, 'katholou' in 74a1 is identifying something which is proper to the demonstration as a demonstration, namely, as an attempt to explain its explanandum and thereby deliver scientific knowledge of it. The use of 'katholou' in 74a1 is not strictly focused on the relation between the subject and the predicate of a given sentence: it focuses on the explanatory connection between explanandum and explanans. Now, the explanandum is presented as a predication in the conclusion of the demonstration, whereas the explanans is the premise pair, the middle term being the most important factor in it. Therefore, the use of 'katholou' in 74a1 focuses on the explanatory relation involving the triplet of terms as presented in a demonstration.

The relation between the subject and the predicate of a given sentence has been the focus in the previous sections of APo I.4. But Aristotle's employment of 'katholou' in 74a1 is introducing something new: the focus on the explanatory claim conveyed in a demonstration. And this employment of 'katholou' will be found thereafter in the APo, starting with the following chapter, in which many passages have

accusative' has the force of introducing an explanatory factor in several occurrences (more on this below), and this is what we should expect from 73b16-18 (cf. 75a35-6). 
'Katholou' with the force of focusing on the explanatory connection: 74a29, 74a32-3, 74a37, b3-4. ${ }^{12}$

The most important of these passages is 74a32-3, which reads thus:

T4: '(i) when do you not know [2R] universally, (ii) and when do you know [2R] simpliciter?' (Barnes's translation, with my addition in the brackets). ${ }^{13}$

In asking 'when do you not know 2R universally?', Aristotle is asking 'when do you not have scientific knowledge about 2R?'. The conjunction 'and' (kai) links the negative question with its positive counterpart. In the latter, the adverb haplôs ('simpliciter', 74a33) retrieves the notion of epistasthai haplôs as defined in 71b9-12. Now, since epistasthai haplôs was defined in terms of grasping explanatory connections, Aristotle's question here - both in (i) and (ii) - is not merely whether one knows or not what is the commensurate subject to which $2 \mathrm{R}$ is coextensively attributed. Aristotle's concern is something stronger, which presupposes that the previous issue about the appropriate subject of $2 \mathrm{R}$ has been already settled: Aristotle's primary issue is whether one knows or not the explanatory factor

12 There is no room to discuss all the occurrences of 'katholou' after 74a1, but I argue that - with the obvious exception of the passages in which formal issues are prominent and ' $k a t b o l o u$ ' is used as in the $A P r$ - many occurrences take up the notion introduced in APo I.4 (ranging over predications) (74a 5 ff., 90a28, $98 \mathrm{~b} 32,33)$ and a significant number of them takes up the stricter application of the notion to demonstrations as in 74a1-3 (74a12, 37, $85 \mathrm{a} 13 \mathrm{ff}$.$) .$

${ }^{13}$ It is clear from the context that $2 \mathrm{R}$, or, more specifically, why

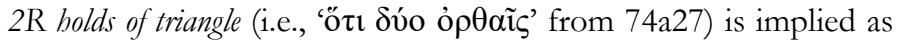
the complement of both occurrences of 'oĩ $\delta \varepsilon v$ ' in 74a32. 
that delivers the appropriate explanation of why $2 \mathrm{R}$ belongs to triangles as triangles. ${ }^{14}$ Once this explanatory factor is grasped, it can be expressed as middle term in a demonstration that will thereby qualify as universal.

The notion of a universal demonstration deserves a more detailed characterisation. A full discussion of it will require a careful examination of $A P o$ I.5 and I.24, which would not fit in this paper. For my purposes, a brief characterisation from the gist of I.5 will be enough.

What criteria does Aristotle observe or presuppose when he applies the term 'universal' to demonstrations, not to predications? Some light is shed on this issue by Aristotle's insistence on some failure conditions: a demonstration fails at being universal if it fails at presenting a universal predication in its conclusion (in the relevant sense introduced in 73a26-33). If one concerned with scientific understanding of $2 \mathrm{R}$ chooses 'isosceles triangle' as minor term, his demonstration fails at being universal because he has not selected the minor term at the appropriate level of generality, that is, a term coextensive with the attribute to be demonstrated (see 74a1-3, 16-17, 74a32-b4). This is true - but is only one part of what Aristotle meant. For, if one corrects this extensional failure by choosing 'triangle' as his minor term, one might still fail at 'knowing universally $2 \mathrm{R}$ of triangle' (74a29), because he might still fail at explaining why $2 \mathrm{R}$ belongs to triangle as triangle $(74 \mathrm{a} 30)$ - and, in fact, knowing universally $2 \mathrm{R}$ of triangle is tantamount to explaining why $2 \mathrm{R}$ belongs to triangles as triangles. 15

\footnotetext{
14 Similarly, Hasper 2006, p. 283: Aristotle is trying to identify 'the unique kind which is the correct conceptual ground for $F$ to belong'.

15 I take 'ö $\tau$ ' in 74a26, 28 as a why, not as a that (pace Ross 1949, p. 526; Barnes 1993, p. 124; Mignucci 2007, p. 169; Fine 2010a, p. 
The most important passage is this (I start with Barnes' translation; after discussion, I will replace it with a different translation):

T5. 'For this reason, even if you prove of each triangle $[\ldots]$ that each has two right angles separately of the equilateral and the scalene and the isosceles-, you do not yet know of triangles that they have two right angles, except in the sophistical way; nor do you know it of triangles universally, not even if there are no other triangles apart from these. For you do not know it of triangles as triangles, nor even of every triangle (except in number- not of every triangle as a form, even if there is none of which you do not know it)' (74a25-32, Barnes's translation).

Scholars take Aristotle as targeting the status of the inference from the particular statements about $2 \mathrm{R}$ to the universal one - i.e., from 'every isosceles triangle has $2 \mathrm{R}$ ', 'every scalene triangle has $2 \mathrm{R}$ ', 'every equilateral triangle has $2 \mathrm{R}$ ', to 'every triangle has $2 \mathrm{R}$ '. Aristotle's would be saying that this merely inductive procedure - even if taken as an exhaustive counting of all species of triangle - does not qualify as an appropriate demonstration because it does not capture the real ground that explains its conclusion. ${ }^{16}$ Aristotle suggests an attempted explanation in which the characteristic of having its extension exhausted by the species isosceles, scalene and equilateral is presented as the

145-7, and many others). This is fine-tuned with the general idea that to have episteme haplôs is to have an explanation.

16 Barnes 1993, p. 124; Mignucci 2007, p. 169; Fine 2010a, p. 1457; Hasper 2006, p. 269-73. 
ground for the explanation of the universal conclusion. Now, the failure in this attempted demonstration - the failure that prevents calling it universal - does not depend merely on the predication displayed in the conclusion. Actually, since the conclusion is a universal predication relating the terms 'triangle' and ' $2 \mathrm{R}$ ', it would make no sense at all to say that the attempted demonstration fails at picking out a universal predication as conclusion. The failure consists in selecting an explanatory factor that is not the appropriate for the desired explanation - an explanatory factor that does not capture why the triangle in itself and as triangle has $2 \mathrm{R}$.

This is how the passage has been taken. ${ }^{17}$ However, it can be interpreted in a more enlightening way - as an attempt to move from particular explanations to a (presumed) universal explanation. Two exegetical points are

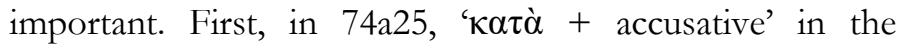

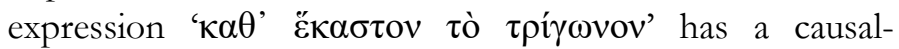
explanatory force and must be taken as tantamount to in virtue of or 'on the basis of (cf. 74a31, 36, b2). The expression tells that the demonstration at stake selects its explanatory factor from what the isosceles itself is as isosceles (or what the equilateral itself is as equilateral, and so on). Secondly, 'ö $\tau$ ' in $74 \mathrm{a} 26$ has the force of why. Thus, Aristotle can be taken as discussing two related issues. First, he discusses the case in which, for each species of triangle, one attempts to explain why it has $2 \mathrm{R}$ in virtue of what it [sc. each species] is in itself - e.g., one claims that isosceles triangle has $2 \mathrm{R}$ in virtue of being a triangle with two sides (or angles) equal to each other. This is the force of the expression 'in virtue/on the basis of

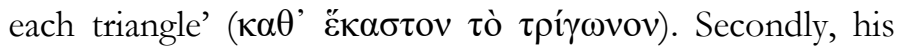

17 See Barnes 1993, p. 123-4; Hasper 2006, p. 270-3; Mignucci 2007, p. 169; Ferejohn 2013, p. 85-90; McKirahan 1992, p. 101-2; Hasper \& Yurdin 2014, p. 131-2; Ross 1949, p. 526; Fine 2010a, p. 143-8; Burnyeat 1981, p. 100. 
discussion extends to the case in which, after amassing those particular explanations about each species of triangle, one attempts to move to a universal demonstration about the triangle by a mere enumeration of the previous explanatory factors. The second procedure, suggested at 74a30-2, has similarities with the inference targeted by the traditional interpretation. But it should not be construed as a move from particular statements to the universal statement. It should rather be construed as an inference from the three particular explanations ('every isosceles triangle has $2 \mathrm{R}$ in virtue of what makes it isosceles', and so on) to a presumed universal explanation in which the explanatory factor will be a mere enumeration of the particular explanatory factors: 'every triangle has $2 \mathrm{R}$ because it is a three-sided plane rectilinear figure with either three sides equal to each other or two sides equal to each other or no side equal to each other'. The translation of the passage will be this:

T5*. 'even if you explain [...] why each species of triangle has $2 \mathrm{R}$ in virtue of what each of them itself is - separately for the equilateral, the scalene and the isosceles - you do not yet know why the triangle has $2 \mathrm{R}$, except in the sophistical way; nor do you know [i.e., explain] it of triangle universally (even if there are no other triangles apart from these). For you do not know [i.e., explain] it of triangle as triangle, nor even of every triangle (except by counting - but not of every triangle as a form, even if there is none of which you do not know it)' (74a25-32, my translation).

One might complain that $\boldsymbol{T 5}$ does not have the expression 'Katholou' explicitly connected with 'demonstration'. However, the context is clearly concerned with discussing cases in which an attempted demonstration 
fails at explaining why a given attribute is predicated of a subject primarily and in itself or qua itself (74a11-12, 16-17, 1819) -and the procedure of explaining why a given attribute belongs to its appropriate or primary subject in itself is identified with a universal demonstration in 74a11-3. Besides, the purpose of the whole chapter I.5, announced just after 74a1-3 (T3), is to detect attempted demonstrations that fail at delivering a primary, universal explanation. ${ }^{18}$ As I said, knowing the cause why $2 \mathrm{R}$ is attributed to triangle qua triangle is equated with knowing universally why $2 \mathrm{R}$ is attributed to triangle (74a28-30, see also 74a35-37, 74b2-4, 85a21-28, b5-7). ${ }^{19}$ Thus, in describing how one fails at knowing universally why $2 \mathrm{R}$ is attributed to triangles as triangles, the passage thereby describes what it is for a demonstration to fail at being universal. Therefore, if we grasp the criteria for downgrading such attempted demonstrations, we thereby grasp, by contrast, what conditions Aristotle imposes on universal demonstrations.

The gist of $\boldsymbol{T} \boldsymbol{5}$ is the following. In order to understand the failure of the attempted demonstrations, one needs to focus on the explanatory relation between the explanans and the predication it is meant to explain, instead of focusing on the mere predicative relation between the

18 See the beginning of APo I.5: "It must not escape our notice that we often happen to make mistakes: what we are trying to explain does not hold primarily and universally in the way in which it seems to have been explained primarily and universally" (74a4-6, my translation). I take 'îं' as the target of the negation ' $\mu$ '’ in $74 \mathrm{a} 5$, the comma after ' $\kappa \alpha \theta$ ó $\lambda$ ov' being entirely misleading. For discussion, see Hasper 2006, p. 253 ff.

19 Differently from many interpreters (Barnes 1993, 124, 184; Mignucci 2007, 169, 227-8; McKirahan 1992 101-2, 175-6; Fine, 2010a, p. 146, n50; Ross 1949, 524, 588), I take the occurrences of 'boti' in those passages with the force of $w h y$, not with the force of that. See Angioni 2016, p. 96-98. 
terms in the conclusion ${ }^{20}$. In order to explain in the appropriate way why the things that have $2 \mathrm{R}$ do have $2 \mathrm{R}$, one needs not only (i) to select the proper subject to which this attribute commensurately belongs, namely, the triangle, but also, and more importantly, (ii) to select the middle term that encapsulates the most relevant feature that makes every triangle as triangle have $2 \mathrm{R} .{ }^{21}$ Consequently, since the explanans is after all presented as the middle term, what makes a demonstration universal is the kind of explanatory relation between the middle term and the conclusion it is meant to explain. What makes episteme universal is the grasp of these appropriate explanatory connections.

\section{III.b) The episteton as universal:}

Aristotle's emphasis on explanatory connections helps us understand what he means by implying that the episteton is universal in $A P o$ I.33, 88b30-1. The episteton is what one gets to know. But, when one grasps a scientific demonstration, what exactly one thereby gets to know? Scholars take the episteton as the conclusion or the fact expressed in the conclusion of the demonstrative syllogism.22 I do not deny that 'episteton' can refer to the fact expressed in the conclusion in many contexts. But I do not

\footnotetext{
20 See Angioni 2016, p. 95-100.

21 I need not discuss here the difficulties about the syllogistic framework of demonstrations. I follow a suggestion made by Mendell (1998), p. 213-4: the syllogistic formulation can be taken as the last step in which - all the previous stages having been settled - the most important explanatory factor is encapsulated in the middle term. See Angioni 2014b, p. 94-100.

22 See (for episteton in 73a22) Mignucci 2007, p. 162; Ferejohn 2013, p. 82; Barnes 1993, p. 110-1; (for episteton in 88b30) Morison (forth.), p. 6-7.
} 
believe that $88 \mathrm{~b} 30$ is one of those contexts. In $88 \mathrm{~b} 30$,

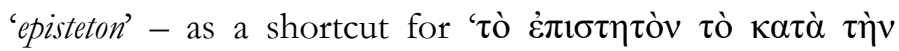

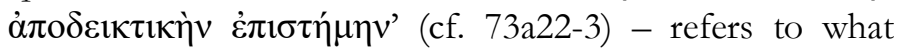
exactly one gets to know when one grasps a scientific demonstration. Now, I argue that what exactly one gets to know when one grasps a scientific demonstration is the triadic relation in which the middle term delivers the most appropriate explanation of the predication it is meant to explain. And this is squared with the concept of episteme that is at stake in $A P o$ since 71b9-12: to have knowledge in its highest form is (or at least involves as its rationale) to explain the explanandum through its cause (cf. 71b9-12) and its appropriate principles (cf. 71b19-23). Having scientific knowledge of each thing involves knowing that its cause is its cause.

Now, one might argue that, even if grasping the explanatory relation is needed for having scientific knowledge of a given pragma (according to 71b9-12), this still does not prove that the explanatory relation is the episteton: for the episteton, one might say, is still the pragma, the predication that occurs as the conclusion of the scientific demonstration. ${ }^{23}$ Now, I agree that the pragma can naturally be called episteton, in the sense of what one can acquire knowledge about. But we also find Aristotle very naturally calling causes episteta (and more episteta than what is explained through them) in Metaphysics 982b2-4 - and this is enough to show that conclusions of demonstrations are not the only items which Aristotle identifies as episteta. Now, since epistasthai haplos was defined as the grasping of the explanatory connection between the pragma and its explanatory factor, it is a natural move to say that the episteton is exactly that explanatory connection, instead of

${ }^{23}$ In favour of this view, one might point to episteton in 73a22. But it is far from clear that episteton in $73 \mathrm{a} 22$ refers to the conclusion. I will discuss this in Section IV. 
one of its components on its own. ${ }^{24}$ Therefore, if a universal demonstration is the demonstration which captures the most appropriate factor for explaining its explanandum, it is a natural move to say (or to imply) that what one gets to know through demonstrative knowledge

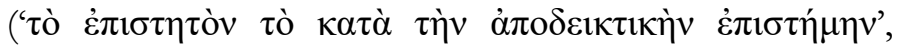
$73 \mathrm{a} 22-3)$ is the appropriate connection between explanandum and explanans. If the discussion at $A P o$ I.33 really takes advantage of the previous discussions in $A P o \mathrm{I}$,

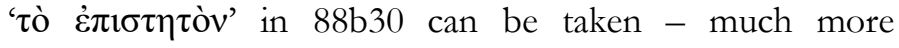
reasonably - as picking out the connection between explanandum and explanans.

Therefore, when Aristotle says that episteme is universal and implies that to episteton has a close connection with the universal, the most reasonable option is to take him as saying that episteme grasps universal demonstrations, which explain their explananda by their appropriate explanatory factors.

\section{THE NECESSARY}

Aristotle uses the expression 'necessary' - or something equivalent, such as 'that which cannot be otherwise' - in several important contexts of $A P o$. In 71b9-12, the notion of something that cannot be otherwise is evoked in the definition of scientific knowledge:

T6. 'We think we have knowledge of something simpliciter (and not in the sophistical way, incidentally), when we think we know of the cause because of which the explanandum holds that it is its cause, and also that it is not

${ }^{24}$ I thank Alan Code for clarity on this point. I will explore it further in section IV in connection with the 'necessary'. 
possible for it to be otherwise' (71b9-12, Barnes's translation modified). ${ }^{25}$

A little further on, Aristotle says that what we know through scientific knowledge (the episteton) is 'necessary' (73a22-3, cf. 71b15-6) - the same claim as found in $\boldsymbol{T} 1$-, and that such a knowledge proceeds from, or depends on, 'necessary principles' (74b5-6) or 'necessary items' (74b135). Let me dwell on the sentence at the beginning of $A P_{0}$ I.4:

T7: 'a demonstration, then, is a syllogism which depends on necessary items' (73a24, my translation).

The term 'items' in my translation might sound excessively cautious, for it seems clear that Aristotle refers to the premises of a demonstrative syllogism or deduction. ${ }^{26}$ It seems safe, then, to take Aristotle as claiming that demonstrative knowledge depends on necessary premises. ${ }^{27}$

\footnotetext{
${ }^{25}$ For discussion of this definition and its 'necessity requirement', see Barnes 1993, p. 89-93; McKirahan 1992, p. 22-23, 81-83; Gifford 2000, p. 172-8; Fine 2010a, p. 139; Goldin 2013, p. 199 200; Ferejohn 2013, p. 68-70; Angioni 2016, p. 84-91; Bronstein 2016, p. 51-57.

26 See Barnes 1993, p. 111, Ferejohn 2013, p. 73, n. 22. McKirahan (1992, p. 81) is right in supplying 'principles' instead of 'premises', but his reason is different from mine, and he does not take the point in the same direction as I do. More on this below.

27 The expression 'necessary premise' (protasis anankaia) is actually used in APo I.30, 87b23-4. However, the claim I will argue for does not cover that occurrence of the expression. See Note 43.
} 
However, this question deserves a more fine-grained discussion. What is exactly (in intensional terms) the bearer of the expressions introducing necessity in all those passages? And, more importantly, what exactly do these expressions convey? One can accept that 'necessary' in $\boldsymbol{T} 7$ is referring to necessary premises. But it is an unjustified step to assume that predications (the sentences that constitute demonstrative syllogisms) are the only bearers of those expressions. And it is a precipitate jump - a jump that unfortunately has been taken for a safe move in the traditional interpretation - to infer or assume that the message conveyed by the expression 'necessary premises' or similar ones in $A P o$ is exhausted by the claim that the premises of a scientific demonstration must be necessarily true predications..$^{28}$ If we agree that the most important point for scientific demonstration is the explanation of the conclusion (instead of a merely sound deduction of it), we must consistently admit that what a premise is conveying to a demonstration is not merely a safe step for truthpreserving deduction, but also, and more importantly, an explanatory factor. Thus, when Aristotle employs the expression 'necessary' or 'necessary premise' to characterise that on which scientific demonstration depends, his target can perfectly well be the explanatory work delivered by the premise instead of its mere truth-value. I will substantiate this point in what follows.

28 See Philoponus 326.3-6, 328.19-22 ff.; Ross 1949, p. 528; McKirahan 1992, p. 82; Kosman 1990, p. 350-4; Lloyd 1981, p. 158; Barnes 1993, p. 110-1, 198; Mendell 1998, p. 196-7; Mignucci 2007, p. 162-3; Ferejohn 2013, p.73n22, 83; Mendelsohn 2019, p. 102-3. Some in this list talk of necessarily true propositions, but they cash out this notion as necessarily true predications. Kosman 1990, p. 356, introduces what he calls 'explanatory necessity', but on closer examination it seems that his proposal collapses into the requirement that 'each extreme term must be connected to the middle by necessity'. 
What makes this question important and pressing is the fact that Aristotle frequently employs the expression 'necessary' (or equivalent ones) as if it encapsulated by itself all that is sufficient for an adequate characterisation of scientific knowledge (or demonstration). In $\boldsymbol{T}$, the expression 'universal' accompanies 'necessary' to demarcate scientific knowledge from doxa. But there are other passages in which either the term 'necessary' (or an equivalent expression) is encapsulating by itself everything that is needed for an adequate characterisation of scientific knowledge, or Aristotle is stumbling in a blatant falsity. The most pressing passage is this:

T8: 'The syllogism must proceed from necessary [items], for from true [items] you can deduce without demonstrating, but from necessary [items] you cannot deduce without demonstrating - this is precisely the mark of demonstration' (74b15-18, Barnes's translation modified).

Now, what this passage claims is clearly false, if 'necessary' is taken merely in the sense of necessarily true predications, as the traditional interpretation understands it. Barnes (1993, p. 126) was very sharp in identifying the trouble. He rephrases the content of $\boldsymbol{T} \boldsymbol{8}$ in this way: '[6] If $P$ is inferred from $\Pi$, and $\Pi$ is necessary, then $P$ is demonstrated.' And his reaction against [6] is correct: 'But (...) [6] is false' (my italics). ${ }^{29}$ However, I do not believe that Barnes' [6] is an accurate paraphrasis of what Aristotle meant. Once we get rid of some well-entrenched

${ }^{29}$ See also Mignucci 2007, p. 171 ('ma quest' affermazione è falsa perché la necessità delle premesse di una deduzione è condizione necessaria e non sufficiente della dimostratività del procedimento'); Smith 2009, p. 60. 
assumptions, we can understand $\boldsymbol{T} \boldsymbol{8}$ in a coherent way without ascribing a blatant falsity to Aristotle. The expression 'necessary' in this context means more than just 'a premise that is necessarily true'. Many approaches agree that it is not enough for demonstrative premises to be necessarily true predications, for it is clear that the premises should also convey an explanation of the conclusion. Some scholars add that, besides being necessarily true, demonstrative premises must have their necessity grounded in per se relations. ${ }^{30}$ Now, the gist of this addition is correct: the necessary truth of the premises must be grounded in per se relations. But this strategy has two drawbacks. First, even necessary truth grounded in per se relations might turn out to be only a sine qua non but not sufficient condition for a demonstrative premise to deliver a scientific explanation (see the examples supplied in Section VI). Secondly, from an exegetical viewpoint, this strategy does not explain what is going on in passages such as $\boldsymbol{T} \boldsymbol{8}$, in which Aristotle seems to be saying that having necessary premises is sufficient for a deduction to be a demonstration.

The important question is this: when Aristotle employs the expression 'necessary' in $\boldsymbol{T} 7$ and, more pressingly, in T8, what does he exactly mean? And what is it that the expression is ranging over? Let us grant that the expression is applied to a premise $P$. But does the expression 'necessary' take $P$ as a mere predication on its own or as an explanatory factor within an explanatory context?

At this point, it is helpful to consider a distinction between two kinds of feature that can be ascribed to a given sentence. The first kind of feature can be ascribed to a sentence on its own, with no need of considering the role that sentence turns out to play in a given context. By contrast, the second kind of feature can only be ascribed to

30 See McKirahan 1992, p. 81ff.; Ferejohn 2013, p. 90-1; Detel 2006, p. 258-9. (This is also suggested in Barnes 1993, p. 120). 
a sentence in relation to the role it plays in a given context. Features such as being true or false are of the first kind. But features such as being enlightening are of the second kind. Consider the sentence: 'quadrupeds are animals'. We can say that it is true - with no need of considering the role it turns out to play in a given context. But if one asks whether that sentence is enlightening or not, the question does not even make sense if we do not provide a context in which it may play or not an enlightening role (one will reply: 'enlightening for what?'). Besides, the right answer will depend on the nature of each context. If one is concerned with the issue 'why do quadrupeds make their progress with a criss-cross movement of their limbs?', it is of course not enlightening to say that 'quadrupeds are animals'. But if one if concerned with the issue 'why do quadrupeds have five senses?', the same sentence can turn out be to enlightening.

True and falsity are features of the first kind. Necessity understood in the traditional way (as a modality ranging over the predicative tie, whatever that means) is also a feature of the first kind. But the question is whether 'necessary' is always employed in this way. My answer is 'no'. I will argue that the adjective 'necessary' - in some important passages - takes a premise $P$ as an explanatory factor within an explanatory context and, consequently, introduces a feature of the second kind.

The issue can be more properly developed in relation to another important sentence from $A P o$ (already alluded to), which belongs to the same argumentative context as $\boldsymbol{T} \boldsymbol{8}$ :

T9. 'demonstrative knowledge depends upon [or proceeds from] necessary principles' (74b5-6, my translation).

What does it mean to say that a principle on which demonstrative knowledge depends is necessary? First of all: the term 'principles', in this context, refers to predicative 
premises that convey an explanatory factor for the conclusion of a demonstration - for demonstrative knowledge ultimately depends on the explanation of what is expressed in the conclusion. ${ }^{31}$ Thus, the issue about what makes a principle on which demonstration depends necessary amounts to ascertaining what makes a given predication a necessary principle for a given demonstration. To be more accurate about this move, consider the questions:

a) what condition does Aristotle observe to call a principle on which demonstration depends necessary?

b) what condition does Aristotle observe to call a predication a necessary principle within a demonstration?

c) what condition does Aristotle observe to call a predication a necessary proposition?

These questions are only meant as a tool for ascertaining whether 'necessary' in the passages above considered

31 I stress that the principles at stake are premises used in a demonstration because there might be (or at least there seem to be) some sort of principles which are not used as premises in demonstrations, such as the principle of non-contradiction etc. See 77a10-12, 92a11-14. Ross 1949, p. 56, 531, 542, 602, defends such a view. For discussion, see Barnes 1993, p. 99-100, 138-9; McKirahan 1992, p. 69-75. Besides, one might argue that the principles recognised in 72a19-20 are existence claims that do not have predicative form. I do not agree with that. But even granting that non-predicative existence claims might be part of a demonstration, I argue that they contribute to the demonstration in a different way than by presenting the most important explanatory factor, which is always expressed by the middle term (cf. 90a6-7). 
introduces a feature of the first kind (which does not depend on the role a predication turns out to play in a given context) or a feature of the second kind (which depends on the role a predication plays in a given context). ${ }^{32}$

Since a principle within a demonstration is a predicative premise, question (a) might be taken as equivalent either to (b) or to (c). The traditional interpretation of $\mathbf{T 9}$ (and related passages) seems to conflate the three questions. My contention is that (b) and (c) are completely different questions - and that question (a) is equivalent to question (b), but is not equivalent to question (c). As I will show, we must distinguish between the predication itself on its own and the predication qua principle, i.e., as performing an explanatory role within an explanation: in question (c) 'necessary' ranges over the predication itself on its own, whereas in question (b) 'necessary' ranges over the predication as a principle. Thus, in the context of question (c), 'necessary' introduces a feature of the first kind (similar to 'true'). But, in the context of question (b), 'necessary' introduces a feature of the second kind (similar to 'enlightening').

The standard answer to question (a) consists in saying that the condition observed by Aristotle is the necessary truth of the predication itself. 33 In other words, question (a)

\footnotetext{
32 Thus, I am not concerned here with the question about what grounds the necessity of a predicative tie etc. This is a different question, that is immaterial to my point here.

33 See Philoponus, 326.3-6; 328.15-24 (but consider 326.7-17); Ross 1949, p. 517, 526, 606; Barnes 1993, p. 110-1, 126; 198; McKirahan 1992, p. 83-4, 125-6; Mignucci 2007, p. 162-3, 171; Smith 2009, p. 59-60. Scholars might argue that issue (c) must be answered on the basis of per se predication: what makes a predication necessary in the relevant way (i.e., to be considered as a principle) is that its necessity is grounded on the per se relation between subject and predicate. But this is a conflation between
} 
is taken as identical to question (c). Now, in order to answer question (c) - and to ascertain whether a given predication is necessary or not -, the relevant focus is only the relation between the subject and the predicate of the sentence: if the predicate is necessarily true of all cases of the subject (whatever this means), the predication is labeled as necessary, with no need of considering its explanatory power for a given explanandum. ${ }^{34}$ Now, suppose that a given predication, which is necessarily true, is also a principle - and thus plays an explanatory role in a given context. But the standard interpretation believes that being a principle is not a sine qua non condition for that predication to be called 'necessary' in the way it is so called in contexts such as $\mathbf{T 9}, 35$ because it interprets 'necessary' in $\boldsymbol{T} \boldsymbol{9}$ merely as necessarily true. The standard notion of a 'necessary principle' turns out to be equivalent to the notion of a predication that is necessarily true and also happens to have an explanatory role in a given context. ${ }^{36}$ Question (a) (namely, what condition does Aristotle observe to call a principle on which demonstration depends necessary?) collapses into question (c) (namely, what condition does Aristotle observe to call a predication a necessary proposition?). Consequently, to call that predication a necessary principle will only be a coincidental

different issues. See previous footnote and its motivation in the text.

${ }^{34}$ What it is for a predicative sentence to be necessarily true is an issue worth being pursued in itself. But it is a different question which has no impact on my point. For discussion, see Malink 2013, p. 27-8.

35 Attention to my italics: there is a difference between being necessarily true and being called 'necessary' in contexts such as T9.

${ }^{36}$ So Barnes 1993, p. 126-30; Mignucci 2007, p. 171. 
aggregation of two features that do not depend on each other, similar to the case in which Dickens is called a British novelist - Dickens is British, and Dickens is a novelist; therefore, Dickens is a British novelist; but Dickens's being British does not depend on his being a novelist, nor the other way around (jokes apart).

But any interpretation along those lines has serious drawbacks. First, it cannot discharge Aristotle from having said a blatant falsity in $\boldsymbol{T} \boldsymbol{8}$ - which Aristotle presents as a rephrasement of the same point made in $\mathbf{T 9}{ }^{37}$ Secondly, as I will argue, it cannot account for the centrality of the necessity requirement in the definition of scientific knowledge, nor for the fact that Aristotle many times employs the terminology of necessity as encoding by itself an adequate characterisation of scientific knowledge. ${ }^{38}$ Thus, if my interpretation can avoid these troubles, it is to be preferred.

This is my main contention: when principles are called 'necessary principles' in $\mathbf{T 9}$, they are taken as principles - so that their being principles is relevant for the truth of the coupled predicate 'necessary principles'. I am not claiming that being a principle must be a sine qua non condition for a predication to be necessary (i.e., necessarily true). I am claiming that being a principle is a sine qua non condition for a predication to be called necessary in the way it is so called in T9.39 For the adjective 'necessary', in $\mathbf{T 9}$ and similar passages, is not applied or applicable to a given predication independently of its being a principle. The principle which

\footnotetext{
37 See the references on note 29.

38 See (besides $\boldsymbol{T} 8) \boldsymbol{T 1}, \boldsymbol{T} 7$, EN VI. 3, 1139b19-21. See the worry about $\boldsymbol{T} 8$ in Smith 2009, p. 60: 'In An. Post. I.6, he proposes an alternative account on which a demonstration would just be by definition a syllogism with necessary premises'.

39 See footnote 35 .
}

Manuscrito - Rev. Int. Fil. Campinas, v. 42, n. 4, pp. 157-210, Oct-Dec. 2019. 
is being called necessary is taken as a principle in being so called: to say that a given predication is a necessary principle amounts to indicating the specific way in which that predication delivers its explanatory role as a principle. This is not similar to the case in which we say 'Dickens is a British novelist'. It is rather similar to the case in which we say about John that he is a good musician: 'good', in this case, is not a predicate applied to John independently of his being a musician; quite to the contrary, 'good' as applied to John in the sentence 'John is a good musician' presupposes that John is a musician and focuses on the way in which John is a musician. 'Good' in that sentence selects a specific way of being a musician - it means that John is good at delivering the activities that allow us to call him a musician.

For the last point, we should pay attention to Aristotle's train of thought in Interpretation 20b35-36 - only replacing 'shoemaker' with 'musician'. Dwelling on his example can be enlightening against a possible confusion about my claim. Consider the three sentences:

(i) 'John is a shoemaker';

(ii) 'John is good';

(iii) 'John is a good shoemaker'.

From the conjunction of (i) and (ii), one cannot conclude (iii) 'John is a good shoemaker', because in (ii) the predicate 'good' does not depend on being a shoemaker, but means morally good, whereas in (iii) the expression 'good', as part of a complex predicate, picks out a specific way of being a shoemaker and thereby depends on the subject's being a shoemaker. Now, John might happen to be a good man (i.e., morally good), as (ii) states. But (ii) is not part of the meaning conveyed in (iii). My point is that ' $p$ is a necessary principle' (implied in $\mathbf{T}$ ) is a statement 
similar to (iii). Consider the parallel case (where ' $p$ ' stands for a predication):

$\left(i^{*}\right)$ ' $p$ is a principle';

$\left(i i^{*}\right)$ ' $p$ is necessary [sc., a necessarily true predication]';

(iii*) ' $p$ is a necessary principle' (as said in $\boldsymbol{T}$ ).

Even when (ii*) is true about a given $p$ (as in all cases within mathematics, cosmology etc.), (ii*) is not part of the meaning of (iii*), because in (iii*) the expression 'necessary' is indicating a way of being a principle and thereby focuses on the explanatory appropriateness of the principle. I hope this clarifies my point. I am not disputing that Aristotle has also been concerned with the necessity of the predicative tie itself in his theory of scientific demonstration. ${ }^{40} \mathrm{My}$ contention is different, namely: what is meant with the employment of the expression 'necessary' in passages such as $\boldsymbol{T}$ 7-T9 is something different from (and somehow stronger than) the concern with necessarily true predications.

Now, this force of the expression 'necessary' is not confined to $\boldsymbol{T} 9$, in which it explicitly modifies the word 'principle' (arche). The same force of 'necessary' or correlated expressions can be found in many other occurrences in which the explanatory appropriateness of the principles is at stake (from $\boldsymbol{T} \boldsymbol{6}$ to $\boldsymbol{T} \boldsymbol{9}$ ). In $\boldsymbol{T} \boldsymbol{8}$, for instance, the word 'principle' (arche) does not occur. But Aristotle takes $\boldsymbol{T} \boldsymbol{8}$ as a rephrasement of the same point conveyed in $\boldsymbol{T} 9$, so that 'necessary' has the same force in both passages: it picks out the premises that are necessary

40 See, for instance, APo I.30, Metaphysics VI.2 and many other passages. 
in the sense of being the principles required for the appropriate explanation. The same holds for $\mathbf{T 6}$, which gives the definition of scientific knowledge. Scientific knowledge about (say) 2R requires two sorts of grasping: (i) knowing, about its explanatory factor, that it is indeed its

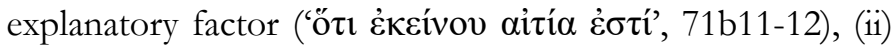
and knowing that this explanatory relation cannot be otherwise. Thus, the fact that this factor is the cause of $2 \mathrm{R}$ (i.e., the real-world relation between the factor and the thing) is what cannot be otherwise, which means that there is only one explanatory factor that counts as the most appropriate or ultimate one..$^{41}$ Since grasping explanatory connections is the definitional mark of scientific knowledge, Aristotle can safely rely on this result as he goes on not only in his ensuing discussions inside $A P o$, but also in other treatises. The expression 'cannot be otherwise' ranges over the explanatory connection not only in $\boldsymbol{T} \boldsymbol{6}$, but also in other passages in which the terminology of 'necessity' seems to encapsulate what is required for an adequate characterisation of the notion of scientific knowledge (as in T7, $\boldsymbol{T 8}$ and $\boldsymbol{T 1}$ ). ${ }^{42}$ The key expression 'necessary' (or equivalent ones) does not introduce modality applied to predications in these passages (T6-T9) - even when the predications involved are in fact necessary, as in all cases within mathematics, theology and cosmology. The key expression has to do with explanatory appropriateness: the principles in a scientific demonstration - whether necessarily true predications themselves or not ${ }^{43}-$ should

41 For this interpretation of Aristotle's definition of scientific knowledge, see Angioni 2016 and Angioni 2014, p. 101.

$42 \mathrm{I}$ am developing this issue in my forthcoming paper 'Aristotle and the necessity of scientific knowledge'.

43 Those sentences will be necessarily true in mathematics (for instance), but will be true only for the most part in natural sciences (cf. 87b22-25). My claim about the expression 'necessary' 
be the predications which are strictly required for the most appropriate explanation of the explanandum at stake.

Let me address two plausible objections. First, it can be objected that my interpretation of 'necessary' (etc.) involves an awkward sense besides the ones officially acknowledged in Metaphysics V.5. Secondly, it can be objected that I am downgrading the relevant notion of necessity - which plays a crucial role in scientific knowledge - to a weaker notion of conditional necessity (or 'hypothetical necessity').

My reply to the first objection is simple. My interpretation does not introduce any awkward sense besides what is officially acknowledged in Metaphysics V.5. In all the passages discussed (T7-T9), the expression 'necessary' has the same core meaning: that which cannot be otherwise. Aristotle himself recognizes this core meaning: it is that on the basis of which other things are called necessary in a more specific way (1015a33-6). The specific force of the expression comes from the context - it depends on the items to which it is applied. Thus, applied to the predication that (e.g.) humans are animals, 'necessary'

as conveying explanatory appropriateness is restricted to the passages explicitly indicated in my paper and does not intend to cover all uses of the expression in Aristotle. More particularly, in APo I.30, Aristotle is using 'necessary' and 'for the most part' as ranging over the predication itself as a predication, and this happens in many other passages. Aristotle's terminology is highly sensitive to context and it is incumbent on us to find the right presuppositions for understanding each occurrence of an expression. It is helpful to consider that the expression ' $\pi \rho$ ó $\tau \alpha \sigma 1 \varsigma$ ' $\alpha v \alpha \gamma \kappa \alpha \tilde{\alpha} \alpha$ ' (a) is used with the force of 'predication that is necessarily true' (in $87 \mathrm{~b} 22-4$ as well as in APr. 25a27 and all occurrences in Aristotle's discussion of modal syllogistic), but (b) is used differently in Topics 155b19-20 ff., namely, with the force of 'premise required for a targeted deduction', and, as I argue in this paper, (c) is used in $89 \mathrm{a} 4$ with the force of 'premise required for the appropriate explanation'. 
means that there can be no situation in which humans will be otherwise, namely, will not be animals. Applied to an explanation saying that the essence of the triangle (or whatever) is the cause of $2 \mathrm{R}$, 'necessary' means that there can be no situation in which that explanatory relation will be different (i.e., no situation in which $2 \mathrm{R}$ would be appropriately explained by a different factor). Besides, as is clear from my previous discussion, we can very comfortably say that necessary principles are those principles without which the appropriate scientific explanation of a given explanandum cannot be attained: they are the principles strictly required for the most appropriate explanation.

This leads me to the second objection. What is labeled 'conditional necessity' in the scholarly literature is a broad and complex subject and there is no room to address its complexity here. But my reply rests on two points. ${ }^{44}$ First, there is no crucial incompatibility between conditional necessity and absolute necessity at least in the level of how Aristotle's terminology usually encodes them. In Metaphysics 1015a20-22, breathing and food-taking are examples of items that are conditionally necessary: they are necessary in the sense that they are something without which humans could not live. This relation of conditional necessity can be formulated in this way: 'if humans are going to live, it is necessary for them to breathe'. But all this is compatible with a formulation that encodes the fact that breathing and food-taking are necessary attributes of humans: 'every human is a breather' and 'every human is a food-taker' express necessary truths in exactly the same way as 'every triangle is a plane figure'.

Second, I reply that the necessary principles really encode real-world relations that are absolutely necessary even if Aristotle's expression seems to present them in the guise of the conditionally necessary. Thus, we can say that

44 See also my remarks in Angioni 2014, p. 102, n. 29. 
the essence of the triangle (or whatever) is a necessary principle in the sense of being that principle without which one cannot appropriately explain why $2 \mathrm{R}$ holds of triangles. This, of course, sounds like conditional necessity: 'if one is going to attain the appropriate explanation of $2 \mathrm{R}$, it is necessary for her to select the essence of the triangle as explanatory factor'. But this is far from being incompatible with the fact that the essence of the triangle is necessarily the appropriate cause of $2 \mathrm{R}$ 's holding of triangles. The semblance of conditional necessity stems from the fact that I am concerned with accounting for the language Aristotle has employed. Indeed, in order to capture what Aristotle has meant with 'necessary' in $\mathbf{T 9}$, it may be useful to resort to formulations that involve conditional necessity: 'if one wishes to attain the appropriate explanation of $2 \mathrm{R}$, it is necessary for her to select the essence of the triangle as explanatory factor'; or 'the essence of the triangle is a principle necessary for attaining the most appropriate explanation of $2 \mathrm{R}$ '. But, as the relation between humans and the attribute of being a breather (or a food-taker) can be captured in a formulation with no appeal to conditional necessity - 'every human is necessarily a breather' (or 'every human is necessarily a food-taker') - in the same way, the relation between the essence of the triangle and the attribute $2 \mathrm{R}$ can be captured in a formulation such as this: 'the essence of the triangle necessarily entails and explains 2R'.

Therefore, 'necessary' applied to explanatory connections really maps real-world connections that are necessary in the non-conditional way. The relation between a given explanandum and its most appropriate explanans is something that cannot be otherwise (cf. 1015b7-8).45 It is

45 Philoponus 22.15-17 has hinted at this when commenting 71b9-12 (T5): 'Likewise those who think that the earth is stationary on account of the swift revolution of the heaven think 
because of this necessity that the premises on which the demonstrative syllogism depends, namely, the premises that encapsulate the most appropriate explanatory factor, cannot be otherwise (cf. 1015b9), i.e., cannot be different premises.

\section{THE EPISTETONAS NECESSARY:}

Let me come back to Aristotle's contrast between episteme and doxa in APo I.33. There is an implied connection between 'necessary' and episteton in 88b29-30 (T1), which is made explicit in 89a10. Now, what does that connection exactly mean?

Aristotle explicitly says that what we scientifically know is necessary $(73 \mathrm{a} 22,71 \mathrm{~b} 15-6, \mathrm{cf} .89 \mathrm{a} 10,88 \mathrm{~b} 30)$. Now, given that scientific knowledge consists in grasping explanatory connections, it is fair to say that what we scientifically know as necessary is the explanatory relation between an explanandum and its explanans. It is this explanatory relation (displayed in the structure of a syllogism) that is picked up by the relevant occurrences of the term 'episteton' - for instance, what we scientifically know is that the triangle's being such and such is the cause why every triangle has $2 \mathrm{R}$ (or that every triangle has $2 \mathrm{R}$ exactly because every triangle is such and such).

Thus, the claim that the 'object' of scientific knowledge (to episteton) is necessary is far from being equivalent to the

they know [i.e., have scientific knowledge], because they believe that this is the cause and they think that the earth could not otherwise be stationary' (McKirahan's translation). What could not be otherwise, according to these guys, is the causal relation between the explanandum (the earth's being stationary) and the explanans (the swift revolution of the heaven). Unfortunately, Philoponus does not develop the point systematically. 
claim that the pragma (either the explanandum or the subject) should be an entity not liable to change (even if the pragma is an entity not liable to change in most or some cases, as in mathematics and theology). ${ }^{46}$ In APo I.33, Aristotle's claims are not primarily focused on the elemental sentences in which a predicate is attributed to a subject. He is focusing on the relation between the explanatory factor - encapsulated in the middle term - and the predication it is meant to explain. It is this relation that, besides being universal (as I discussed in my previous section), cannot be otherwise. The middle term must capture the most appropriate explanatory factor for the explanation. If a different middle term is taken, one might still have true predications, one might even attain some explanation of his explanandum (cf. 78b23-32), but one fails at achieving scientific knowledge because one fails at attaining the most appropriate explanation. One is then still at the level of doxa (see examples in the next section). And we can see how comfortable Aristotle was when he employed the term 'doxa' to refer to his predecessor's and rival's philosophical theories.

Let me address a helpful objection. As I suggested in my last paragraph (and am going to develop in the next section), the contrast between episteme and doxa in APo I.33 is a constrast between explaining something through its strictly appropriate principles and explaining it through other principles that fall short of being the most appropriate for the explanandum in question. This is what Aristotle means by saying that episteme deals with the necessary, whereas doxa deals with what is true, but can be

46 My claim applies to any interpretation of pragma: as the explanandum expressed in a predication, or as the subject within that explanandum, or as the attribute to be explained (or even as the subject-matter broadly taken). For discussion of these ways of taking pragma, see Bronstein 2016, p. 54-6. 
otherwise. Now, one might be tempted to take my claims as equivalent to saying that explanatory sentences of the form ' $p$ because of $q$ ' are necessary truths in the case of episteme but non-necessary truths in the case of doxa. Then, one might object that, when $q$ is not the most appropriate principle for $p$ (in the level of doxa), it is not correct to say that ' $p$ because of $q$ ' is true but non-necessary: ' $p$ because of $q$ ' turns out to be false.

First, as a preliminary remark before my answer, I stress that my point does not depend on formulating explanatory relations as sentences of the form ' $p$ because of $q$ ' and ascribing necessary truth to them. Actually, it is far from clear how Aristotle's terminology encodes the notion of truth applied to the explanatory relation between explanandum and explanans. ${ }^{47}$ Indeed, Aristotle uses explanatory sentences of the form ' $p$ because of $q$ ', but he does not give any prominence to them in the official treatment of scientific demonstration. He takes the relation between explanandum and explanans as to be encoded in the structure of the demonstrative syllogism: the premise pair is the explanans, whereas the conclusion is the explanandum. Although it is obvious to us that explanatory syllogisms can be transformed into explanatory sentences of the form ' $p$ because of $q$ ', it is important to keep in mind that Aristotle has never prescribed that move. ${ }^{48}$ This is important because the issue here is how Aristotle employs

47 I have dealt with this issue in Angioni 2014b, p. 75-83. See a helpful discussion in Morison's contribution in this volume.

48 One might think that 'knowing the dioti' (as found in, e.g., 78a22) can be taken as equivalent to 'knowing ' $[p]$ because of $[\mathrm{q}]$ '. However, 'to dioti' seems to be an abbreviated way of referring to the middle term that expresses the primary explanatory factor (78b2-3). See Angioni 2018, p. 164. Thus, 'knowing the dioti should be understood as 'grasping the primary explanatory factor on which our explanandum depends'. 
'necessary' and correlated expressions: I am trying to show that Aristotle's terminology can easily lead to misunderstandings if taken without due attention to its context. In order to understand what exactly 'necessary' and correlated expressions mean in the passages discussed, it is important to keep in mind Aristotle's way to parse explanatory relations.

Now, my answer to the objection is that explanatory appropriateness for Aristotle comes in degrees: it is liable to the more and the less. Besides the principles that are exactly the appropriate ones for their explananda (cf. 76a5-6), Aristotle recognises principles or causes that are more proximate or more remote to the explanandum, the former being causes explanatorily prior to the latter (Physics 195b21-25, Metaphysics 1044b1-3). Thus, Aristotle's attitude towards sentences of the form ' $p$ because of $q$ ' would probably be this: he would request an adverbial complement modifying the 'because' to make clear in what point of the appropriateness scale $q$ claims to be located. It is hard to know whether Aristotle would be inclined to state that ' $p$ because of $q$ ' (without such a complement) is merely false when $q$ is not the most appropriate explanatory factor for $p$. Aristotle would probably say that ' $p$ exactly because of $q$ ' is false when $q$ is not the most appropriate explanatory factor for $p$, but he would hardly be inclined to conclude that $q$ does not have any explanatory connection with $p .49$

${ }^{49}$ This attitude towards explanation is what probably accounts for
curious pieces of terminology such as 'true but not enlightening'
(as found in Eudemian Ethics 1216b32-3, 1220a16-18, 1249b5-6)
and the comparative and superlative forms of 'true' (as found in
APo 100b11; Politics 1290a24; Metaphysics 993b28; Gen.Corr.
$329 \mathrm{a} 21 ;$ Metaphysics $1009 \mathrm{a} 3$; NE 1107a31). Presumably, Aristotle
would explain what the expression 'more true' means in the same
way as he has explained other comparatives such as 'more
knowable': $X$ is more knowable than $Y$ if $X$ is the cause through 
Consider this example of the form ' $p$ because of $q$ ': 'walls do not breathe because they are not animals' (78b1528). Aristotle says that such an explanation does not capture the explanatory factor - i.e., the primary explanatory factor for the explanandum. ${ }^{50}$ But he agrees that an explanation of this kind grasps at least an important sine qua non condition for the explanandum to hold and thereby might be important to put a researcher into the right track.

\section{MAKING BETTER SENSE OF THE CONTRAST IN ITS CONTEXT:}

The contrast between episteme and doxa in APo I.33 continues with the following words:

T10. '(i) It remains that it is opinion that is concerned with what is true or false but can also be otherwise. (ii) This is a belief in a premise which is immediate but not necessary' (89a2-4, Barnes's translation modified).

First of all, it is important to remark that scholars are despondent about step (ii): if 'necessary' means 'necessarily true', and if being immediate is tantamount to imposing by itself the credentials of its truth, how an immediate

which $Y$ becomes known (72a29-32 ff.; 982b2-4); similarly, one might say that $q$ is more true than $p$ in the sense that $q$ is the cause through which $p$ becomes scientifically known. This is what Aristotle himself suggests at Metaphysics 993b23-31 (and it is a promising way to understand similar language employed at $A P o$ 100b11).

${ }^{50}$ See Angioni 2018 for this interpretation of the passage. 
proposition could be at the same time a non-necessary proposition? 51

It would not work to appeal to attenuated senses of 'immediate' - e.g., 'immediate' in the sense of not justified, but assumed in a (dialectical) argument because some authority endorses it, 52 or 'immediate' as referring to statements about singular things grasped through perception. For Aristotle does not seem to be concerned with those kinds of statement anywhere in $A P o$. I.33, nor are they central in the $A P o$ as a whole ${ }^{53}$ - and restricting opinion to those kinds of statements would be contrary to obvious facts. Moreover, the difficulty is much more pressing than such strategies imply, for there are important passages where Aristotle insists on a very similar idea, namely: premises that are immediate in some epistemologically relevant sense are still not enough for having scientific demonstration. We read in APo I.9:

T11: 'Since it is clear that you cannot demonstrate anything except from its own principles, [...], scientific knowledge is not simply a matter of explaining something from what is true and

51 See the despair about the passage in Barnes 1993, p. 199: 'it should be excised'. Mignucci (2007, p. 245): 'Inspiegabile è poi l'ulteriore restrizione, compiuta in $89 \mathrm{a} 4$, alle proposizione immediate'.

52 As found in Philoponus (325.3-9), whose interpretation is unclear.

53 Statements about singular things grasped through perception are important in the investigation stage, but are unable to deliver scientific knowledge (see $A P o$ I.31). 
indemonstrable and immediate' (75b39-40, Barnes's translation, modified). ${ }^{54}$

As I will show, the terminology employed in $\boldsymbol{T} 10$ becomes much more significant in the light of $\boldsymbol{T} 11$. I have argued that the first chapters of $A P o$ have characterised scientific knowledge as the grasp of explanatory connections through explanatory factors that are necessary (71b12, 73a21-24, 74b5 ff., 75a12-15). But - as Aristotle says at the beginning of $A P o$ I.33 - besides the necessary [sc. explanatory factors], there is also 'what is true, but can be otherwise'. The last expression can be taken differently in different contexts. When a sentence such as 'I believe that Socrates is seated' is taken as conveying true doxa, what can be otherwise is Socrates's real situation: he is seated, but he might stand up etc. However, take the following sentence as expressing doxa: 'I believe that being a triangle with two sides equal to each other is the cause by which the isosceles triangle has 2R'. In this case, what can be otherwise is not either the fact that isosceles are triangles with two sides equal to each other or the fact that isosceles have 2R. 'What is true [in some sense], but can indeed be otherwise', in this case, refers to the explanatory claim qua explanatory. .5

Now, why should we believe that step (i) of $\boldsymbol{T} 10$ takes the expression 'what is true (or false), but can be otherwise' in the first way, as if Aristotle were saying that opinion in general (by its own nature) is a cognitive state that can only

54 A similar claim is found a litte further in the same chapter: 'We think we understand something if we possess a deduction from some true and primitive items. But this is no so' (76a28-30, Barnes's translation). See also the last sentence at the baffling passage 75a13-7.

55 'The 'Ko'́ in 89a3 is better understood as 'indeed' (and in 88b33 too). 
deal with contingent predications? Why should Aristotle restrict opinion to that? As a matter of fact, Aristotle does not restrict opinion to contingent predications. ${ }^{56}$ The objects of many false opinions are not contingent (e.g., that the diagonal is commensurate with the side)..$^{57}$ The expression 'what is true (or false), but can be otherwise' in $89 \mathrm{a} 2-3$ is employed in the second way: Aristotle is saying that it is opinion - not any other state - that is committed to explanatory factors that involve truth, but can indeed be otherwise. Accordingly, step (ii) of $\boldsymbol{T} 10$ does not pick up the general notion of opinion, but specifies what opinion is when it deals with explanatory factors: step (ii) specifies that those factors come in premises that, even being immediate, are not explanatorily necessary. The explanatory claim at the level of doxa can be said to involve truth not only in the sense that the elemental predications involved are themselves true, but also, and more importantly, in the sense that at least some explanation has been delivered (even if not the most accurate one). However, the explanatory story can - and, indeed, should - be otherwise: a different explanatory factor must be found, so that what was irrelevant in the original explanation is abandoned (e.g., the characteristic of having two sides equal to each other) and replaced with what is ultimately appropriate.

Thus, 'protasis' in $\mathbf{T 1 0}$ does not refer to a proposition taken in itself with no attention to its explanatory role within a given context, but to a premise used as an explanatory principle in an attempted demonstration. ${ }^{58}$ The

56 According to Nicomachean Ethics 1111b31-33, doxa seems to have an unlimited range.

57 See Metaphysics $990 \mathrm{~b} 22$ (= 1079a18), $990 \mathrm{~b} 28$ (=1079a25), 1078b10, 13, 1087b31, 1090b29; Physics 213a22 (opinions about the void) and de Anima 403b22 (opinions about the soul).

58 The Greek $\pi \rho$ ó $\tau \alpha \sigma 1 \zeta$ can be understood as proposition or as premise, depending on the context (for discussion, see Charles 
notion of a premise which is immediate (in an epistemically relevant sense) but not required for the most appropriate explanation of a given explanandum is perfectly in line with the notion of premises that are true and immediate without capturing the appropriate principle of their explanandum as such (75b37-76a7, cf. T11). It is helpful to consider again the distinction between two kinds of feature ascribed to propositions or sentences, as I have advanced in Section IV. 'Immediate' both in $75 \mathrm{~b} 40$ (T11) and 89a4 (T10) introduces a feature that can be ascribed to propositions independently of the role they play in a given context: immediate propositions are those that cannot be demonstrated by any explanatorily prior propositions, or (as standard interpretations might prefer) those that impose the credentials of their truth by their content alone..$^{59}$ On the other hand, 'necessary' in 89a4 (T10) is used in the same way as in $\boldsymbol{T} 7-\boldsymbol{T} \boldsymbol{9}$, namely, as introducing a feature that depends on the role a given proposition plays in a given context - in this case, the explanatory role it is meant to play in an explanatory context.

and Crivelli, 2011). I argue that it should be taken as an explanatory premise in the context of $\boldsymbol{T} 10$.

59 The first option is presumably more accurate (as Breno Zuppolini has pointed to me), but it does not modify my contention: when we say that a proposition is indemonstrable, we are looking for premises from which it could be explained - but this is different from considering its explanatory appropriateness for a given explanandum. Besides, what I am saying about 'immediate' is limited to those occurrences discussed in the paper (75b40, 78a26, 89a4). Sometimes, 'immediate' is entangled with explanatory appropriateness $(72 \mathrm{a} 7-8$, as one of the six requirements for the premises of scientific demonstration). A crucial point in I.9 is that 'immediate', if interpreted in a different way, can be dangerously manipulated by the sophist interested in a false semblance of scientific explanation. 
Situations of the kind suggested in $89 \mathrm{a} 4$ have played a significant role in $A P o$ - for instance, in T11 ('scientific knowledge is not simply a matter of explaining something from what is true and indemonstrable and immediate'). ${ }^{60}$ Explanatory factors that are immediate [propositions] but not [explanatorily] appropriate called for Aristotle's attention because their immediacy is seductive and might mislead one to believe that an ultimate explanation has been reached. ${ }^{61}$ One example is found near T11: the immediate proposition used in Bryson's squaring of the circle. But since this case cannot be reasonably discussed within the limits of this paper, ${ }^{62}$ I will take other examples. First, consider the syllogism below, which is not found in Aristotle's text but has some didactic appeal: ${ }^{63}$

Major Premise: Every mammal is mortal. Minor Premise: Every human being is mammal. Conclusion: Every human being is mortal.

If one prefers a syllogism actually found or at least outlined in Aristotle's text, I point to 74a13-16:

${ }^{60}$ See a similar point in 76a28-30 and 78a26-28.

${ }^{61}$ See also 74b25-6 and my point in Angioni 2014, p. 103.

62 On this, see Mueller 1982, p.161-4; Fait 2007, 154; Hasper 2013, 314-9; Angioni 2016, p. 92, 100. There is agreement on this basic point: Brison's squaring of the circle is a sound deduction of its conclusion from premises that are true and immediate (as capturing a true intuition about continua in general). There is disagreement about details in Aristotle's description of what is wrong with Brison's deduction.

63 See Hankinson 1998, p. 161, for an excellent use of this example. 
Major Premise: Lines cutting a third line in a right angle are parallel.

Minor Premise: Two lines perpendicular to a third line cut the third line in a right angle.

Conclusion: Two lines perpendicular to a third line are parallel'. ${ }^{64}$

The predications in both syllogisms are necessarily true. Besides, one might say that the minor premise is immediate in both syllogisms - or at least in the geometrical example, in which the minor premise seems to be (at least part of) the definition of its subject. However, it is clear that the minor premise is not necessary for the appropriate explanation of its explanandum in neither of those syllogisms. The characteristic of being mammal is not what makes humans mortal. This characteristic is not even relevant for the desired explanation. Similarly, the characteristic of cutting the third line in right angles is not what accounts for those lines being parallel to each other. ${ }^{65}$ For these reasons, someone that advances the explanatory claims encapsulated in those syllogisms is still on the level of doxa. But this does not imply that the predications involved in the syllogisms are contingent, i.e., not necessarily true - let alone that the propositions are contingent because their objects are liable to change through time. Furthermore, being in the level of doxa does not imply that anyone entertaining those explanatory claims

64 Another example, outlined in 85b6 (cf. 85a27-28), in this: 'every plane rectilinear figure with three sides and exactly two angles equal to each other has 2R; every isosceles triangle is a plane rectilinear figure with three sides and exactly two angles equal to each other, therefore, every isosceles triangle has $2 \mathrm{R}$ '. I have examined this case in Angioni 2016, p. 96-99.

${ }^{65}$ I have dealt with this point in Angioni 2014, p. 97. See also Hasper 2006, p. 256. 
has doubts about the truth-value of each of the predications involved in the syllogisms. Being in the level of doxa can even be the state of the expert who, notwithstanding her expertise in a given domain, has not yet attained the most appropriate explanation of a given explanandum within that domain. Her cognitive state will qualify as doxa concerning that particular explanandum, but this does not imply that her mastery over the domain is only doxa. ${ }^{66}$ And 'this agrees with how things manifestly are' (89a4-5). ${ }^{67}$

Thus, when Aristotles says that 'opinion is unstable' (89a5-6), there is no need to take 'unstable' (abebaion) as restricted to the truth-value of predicative sentences. Opinions can also express explanatory claims (cf. 89a1316). Now, when they express explanatory claims, they are unstable not because the truth-value of the elemental predications involved is uncertain or liable to change, but because the explanatory factor advanced in the claim is not the most appropriate one. Of course, many cases of opinion can be taken as unstable because their subjectmatter is contingent. But there is no need to restrict opinion to subject-matters of this sort. If an opinion

${ }^{66}$ As I have said (note 10), 'having scientific knowledge of something is employed by Aristotle in relevant contexts as equivalent to having the most appropriate explanation of a given explanandum, but not as equivalent to having mastery over a given domain. Someone might be an expert with mastery over a domain without having the ultimate explanation of some explananda in that domain.

${ }^{67}$ It is intuitively true that most experts in a given domain have only doxa about some explananda in the domain, and this does not jeopardise their expertise. Someone can be a Nobel laureate in medicine but have only doxa about what a recalcitrant disease is. The fact that her doxa is still superior to the doxa of the laymen does not modify the point. 
conveys an explanatory claim about kinds, it is unstable too, but not because it covers contingent matters, nor because it involves uncertainty about the truth of the elemental predications involved in the claim, but because the explanatory tie is not appropriate enough. ${ }^{68}$ The syllogisms given above in this section are good examples of this situation. To use the image from Plato's Meno (97e2-98a8), the explanatory tie (the aitias logismos, 98a3-4) was not strong enough to fix the opinions on the ground and settle them as pieces of scientific knowledge. ${ }^{69}$

\section{CONCLUSION}

What is depicted as doxa, in contrast to scientific knowledge in APo I.33, is an explanatory claim that attempts to explain its explanandum through a cause that is not the most appropriate one - not the required one. In other words, the relevant kind of doxa involved in the contrast is an attempted explanation relying on premises that, even when they are immediate (imposing their truth by themselves) and necessarily true, are not necessary in the relevant way, i.e., are not the required ones for the most appropriate explanation of the targeted explanandum.

A further advantage of this interpretation is that it explains how Aristotle is entitled to use 'doxa' to refer to

${ }^{68}$ Similarly, someone not convinced of the appropriateness of an explanatory claim might object that 'this is not necessary' or 'not

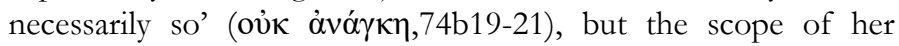
objection is not any of the elemental propositions, but the explanatory tie between them - it is the explanatory tie that is not the necessary one. See Angioni 2014, p. 102.

${ }^{69}$ I disagree with Barnes 2014, p. 87, when he comments 71b9-12 on the light of Plato's Meno ('What distinguishes knowledge from belief is not causality but necessity'). 
rival scientific theories or philosophical doctrines. ${ }^{70} \mathrm{I}$ am not suggesting that all those rival doctrines or theories should be taken at the same level. All I am suggesting here is that philosophical doctrines and scientific theories essentially involve explanatory claims, for they are attempts to explain why things are the way they are. When Aristotle uses ' $d o x a$ ' to refer to them, he is not thereby implying that they are restricted to contingent subject-matters. He is only implying that they have not attained the utmost level of explanatory appropriateness.

Of course, what Aristotle says about doxa in APo I.33 is not exhaustive. There is a lot about doxa as a cognitive state in De Anima III, besides several passages scattered in other works. And there are many things to be explored about the relation between doxa and the notion of belief as the generic attitude of taking-to-be-true, which is normally expressed by 'bupolepsis' rather than 'doxa' in Aristotle's terminology. ${ }^{71}$ However, in the context of APo I.33, the contrast between doxa and episteme is restricted to the domain of explanation and hinges on the explanatory appropriateness of explanatory claims. ${ }^{72}$ What makes an explanatory claim be at the level of doxa is the lack of 'the necessary principle', i.e., the lack of the middle term that captures the most appropriate explanatory factor and

\footnotetext{
70 See de Caelo 293a26, 298b25, 306a8; Metaphysics 984a2, 987a33, 991a19, 1009a6, 23; b16, 29, 36; 1010a1, 10 (and, especially about the Theory of Forms, Metaphysics 990b22 = 1079a18, $990 \mathrm{~b} 28$ =1079a25, 1078b10, 13, 1087b31, 1090b29); Pbysics 213a22; de Anima 403b22.

71 See Moss \& Schwab 2019, p. 18-24.

72 Similarly, in APo I.31, far from telling us all we need to know about perception in general, Aristotle is only highlighting the relation between perception and the grasp of universal explanatory connections.
} 
thereby turns the explanatory claim into a universal demonstration of its explanandum. ${ }^{73}$

\section{REFERENCES:}

AngIOnI, L. 2013. Knowledge and Opinion about the Same Thing in APo A-33. Dois Pontos 10.2, 255-290.

2014. Aristotle on Necessary Principles and on Explaining X through X's essence. Studia Philosophica Estonica 7.2, 88-112.

2014b. Demonstração, Silogismo e Causalidade, in Angioni, L. (ed.), Lógica e Ciência em Aristóteles, Campinas: PHI, 61-120.

2016. Aristotle's Definition of Scientific Knowledge (APo 71b9-12). Logical Analysis and History of Philosophy 19, 140-166.

2018. Causality and coextensiveness in Aristotle's Posterior Analytics 1.13. Oxford Studies in Ancient Philosophy LIV, p. 159-185.

2018b. Geometrical premises in Aristotle's Incessu Animalium and kind-crossing, Anais de Filosofia Clássica 24, 53-71.

(forth.). Aristóteles e a necessidade do conhecimento científico, Discurso.

73 Previous drafts of this paper were discussed many times with many people. I thank Alan Code, Michail Peramatzis, Laura Castelli, David Bronstein, Raphael Zillig, Inara Zanuzzi, Ben Morison, Ryan Putzer, Breno Zuppolini for criticisms, objections, encouragements and suggestions. Special thanks are due to Tim Clarke at the final stage of my writing. 
BARNES, J. 1993. Posterior Analytics. Oxford: Oxford UP. 2014. Aristotle on knowledge and proof. In Proof, Knowledge and Scepticism. Oxford: OUP, 73-94.

BerTi, E. (ed.). 1981. Aristotle on Science - The Posterior Analytics. Padova: Antenore.

Bronstein, D. 2016. Aristotle on Knowledge and Learning. Oxford: Oxford UP.

BURNYEAT, M.F. 1981. Aristotle on Understanding Knowledge. In: Berti, E.(ed.). Aristotle on Science- The Posterior Analytics. Padova: Antenore, 97-140.

2011. 'Episteme', In B. Morison \& K. Ierodiakonou, Episteme etc.: Essays in Honour of Jonathan Barnes, Oxford: OUP, p. 3-29.

Charles, D. 2000. Aristotle on Meaning and Essence. Oxford: Oxford UP.

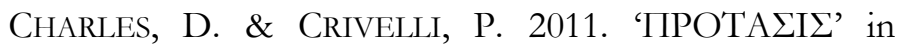
Aristotle’s Prior Analytics. Phronesis 56, 193-203.

DeTEL, W. 2006. Aristotle's Logic and Theory of Science, in Gill, M.-L. \& Pellegrin, P. (edd.), A Companion to Ancient Philosophy, Oxford: Blackwell.

FAIT, P. 2007. Le confutazione sofistiche. Roma-Bari: Laterza.

FEREJOHN, M. 1994. The Immediate Premises of Aristotelian Demonstration, Ancient Philosophy 14, 7997.

2013. Formal Causes. Oxford: Oxford UP.

FINE, G. 2010a. Aristotle on Knowledge. In: Fronterotta, F. (ed.). La Scienza e le cause a partire dalla Metafisica di Aristotele. Napoli: Bibliopolis, 121-156. 
2010b. Aristotle's Two Worlds: Knowledge and Belief in Posterior Analytics I.33. Proceedings of the Aristotelian Society 110, 323-46.

GIFFORD, M. 2000. "Lexical Anomalies in the Introduction to the Posterior Analytics, Part I", Oxford Studies in Ancient Philosophy 19, p. 163-224.

Goldin, O. 1996. Explaining an Eclipse: Aristotle's Posterior Analytics 2.1-10. Ann Arbor: University of Michigan Press.

2013. Circular justification and explanation in Aristotle. Phronesis 58, 195-214.

Hankinson, R. J. 1998. Cause and Explanation in Ancient Greek Thought. Oxford: Oxford UP.

HASPER, P. S. 2006. Sources of delusion in Analytica Posteriora I 5. Phronesis 51, 252-284.

2013. Between Science and Dialetic: Aristotle's Account of Good and Bad Peirastic Arguments in the Sophistical Refutations. Logical Analysis and History of Philosophy 15, 286-322.

Hasper, P. S. \& Yurdin, J. 2014. Between Perception and Scientific Knowledge: Aristotle's Account of Experience, Oxford Studies in Ancient Philosophy 47, 119-150.

INWOOD, BRAD. 1979. A Note on Commensurate Universals in the Posterior Analytics, Phronesis 24, 320-329.

Kosman, L. A. 1973. Explanation, Understanding and Insight in Aristotle's Posterior Analytics. In: Lee, H./ Mourelatos, A./ Rorty, R. (eds.). Exegesis and Argument. Van Gorcum: Assen. 
1990. Necessity and Explanation in Aristotle's Analytics, in Devereux, D. \& Pellegrin, P. (edd.), Biologie, logique et métaphysique chez. Aristote, Paris: Editions du CNRS, p. 349-364.

Lennox, J. G. 2001a. Divide and Explain: the Posterior Analytics in practice. In: Lennox, J. G. (ed.). Aristotle's Philosophy of Biology. Cambridge: Cambridge UP.

2001b. Between Data and Demonstration: the Analytics and the Historia Animalium. In: Lennox, J. G. (ed.). Aristotle's Philosophy of Biology, Cambridge UP, 2001.

Lesher, J. H. 2001. Aristotle on $\dot{\varepsilon} \pi \imath \sigma \dot{\eta} \mu \eta$ as understanding. Ancient Philosopby 21, 45-55.

LLOYD, A. C. 1981. Necessity and Essence in the Posterior Analytics. In: Berti, E. (ed.). Aristotle on Science - The Posterior Analytics. Padova: Antenore, 157-171.

MALINK, M. 2013. Aristotle's Modal Syllogistic. Harvard University Press.

Matthen, M. 1981. The Structure of Aristotelian Science. In: Matthen, M. (ed.). Aristotle Today: Essays on Aristotle's ideal of science. Edmonton: Academic Printing \& Publishing, 1-23.

McKirahan, R. 1992. Principles and Proofs. Aristotle's Theory of Demonstrative Science. Princeton: Princeton UP.

Mendell, H. 1998. Making Sense of Aristotelian Demonstration. Oxford Studies in Ancient Philosopby 16, 161-225.

Mendelsohn, Joshua. 2019. Aristotle on the Necessity of What We Know. PhD Dissertation: University of Chicago. 
MignuCCI, M. 2007. Aristotele - Analitici Secondi. Roma-Bari: Laterza.

MORISON, B. Forthcoming. Aristotle on the distinction between what is understood and what is believed, in Salmieri, G. (ed.), Knowing and Coming to Know: Essays on Aristotle's Epistemology, Pittsburgh University Press.

Moss, J. \& SCHWAB, W. 2019. The Birth of Belief. Journal of the History of Philosopby 57 (1), 1-32.

Mueller, I. 1982. Aristotle and the Quadrature of the Circle. In: Kretzmann, N. (ed.). Infinity and Continuity in Ancient and Medieval Thought. Cornell: Cornell UP, 146-164.

Peramatzis, M. Forthcoming. Aristotle on Knowledge \& Belief: Posterior Analytics I.33, in Salmieri, G. (ed.), Knowing and Coming to Know: Essays on Aristotle's Epistemology, Pittsburgh University Press.

Philoponus. 1909. In: Wallies, M. (ed.). Aristotelis analytica posteriora commentaria (commentaria in aristotelem graeca vol. XIII). Berlin: Walter de Gruyter. 2008. On Aristotle Posterior Analytics 1.1-8. Translated by Richard McKirahan. London: Bloomsbury.

Ross, W. D. 1949. Aristotle's Prior and Posterior Analytics. Oxford: Oxford UP.

SMITH, R. 1984. Immediate propositions and Aristotle's proof theory. Ancient Philosophy 6, 47-68.

2009. Aristotle's theory of demonstration. In: Anagnostopoulos, G. (ed.). A Companion to Aristotle (Blackwell Companions to Philosophy). Oxford: WileyBlackwell, 51-65.

TAYLOR. C. C. W. 1990. Aristotle's epistemology. In: S. Everson (ed). Epistemology. Cambridge UP,116-142. 
Zuppolini, B. 2018. Aristotle on Per Se Accidents. Ancient Philosophy 38, 113-135.

$$
(\mathrm{sc}) \mathrm{BY}
$$

Manuscrito - Rev. Int. Fil. Campinas, v. 42, n. 4, pp. 157-210, Oct-Dec. 2019. 